\title{
Grupos de pesquisa: o acolhimento aos habitantes, visitantes e transeuntes de um ambiente virtual
}

\section{Research groups: attention to the inhabitants, visitors and passers-by of virtual environment}

\section{Glaucia da Silva Brito ${ }^{[a]}$, Ariana Chagas Gerzson Knoll ${ }^{[b]}$, Michele Simonian ${ }^{[c]}$}

[a] Professora Doutora do Departamento de Comunicação Social e dos Programas de PósGraduação em Educação e em Comunicação da Universidade Federal do Paraná (UFPR), Curitiba, PR - Brasil, e-mail: glaucia@ufpr.br

[b] Professora, Mestre pela Universidade Federal do Paraná (UFPR), Mafra, SC - Brasil, e-mail: ariana_chagas@hotmail.com

[c) Professora, Mestre pela Universidade Federal do Paraná (UFPR), PR - Brasil, e-mail: simimi@hotmail.com

\section{Resumo}

Este artigo é fruto da análise de uma experiência bimodal planejada em grupo de estudos inserido no contexto de um grupo de pesquisa chamado Grupo de Estudos Professor Escola e Tecnologias Educacionais (Gepete) e seu grupo de ingresso chamado Gepetinho. A 
temática de estudo centrou-se na tríade professor, escola e tecnologias educacionais. Sendo assim, os dados analisados são advindos da estruturação de um grupo de estudos que se desenvolve ao longo de um ano, tornando-se um grupo de pesquisa, cadastrado no CNPq, e que se dedica a pesquisas relativas às necessidades, conflitos e desafios inerentes ao educar na Sociedade da Informação. Tem seu foco na formação continuada de professores, basicamente em três linhas de pesquisa: educação a distância, formação de professores para o uso das TIC e tecnologia digital em música. Buscamos discutir aspectos necessários na proposição de formação continuada do professor, considerando o seu desejo em desenvolver-se profissionalmente por meio de formações bimodais e estrutura de grupo de pesquisa. Para a referida discussão e embasamento utilizamos autores como: Aretio (2001), Gadotti (2003), Scherer (2005), Brito (2006), Brito e Purificação (2006) e Behrens (2007). A análise permitiu evidenciar que independente das categorias (habitantes, transeuntes ou visitantes) em que professores orientadores e tutores se encaixem, tanto no Gepete quanto no Gepetinho houve a orientação e o amparo aos participantes. As ações e aprendizados foram se construindo de maneira cooperativa e colaborativa, nascidas do desejo e do compromisso profissional de cada um dos participantes em construir uma educação comprometida com seu tempo.

Palavras-chave: Formação de professores. Bimodal. Tecnologias educacionais. Grupo de pesquisa.

\section{Abstract}

This article is the result of the analysis of a planned bimodal experience in study group inserted in the context of a research group called Study Group Teacher School and Educational Technologies (Gepete) and its ingression group called Gepetinho. The theme set of the study has been centered in the triad teacher, school and educational technologies. Thus, the analysed data proceed from the structuration of a study group that develops along a year, becoming a research group, registered in the $\mathrm{CNPq}$, and that dedicates itself to research related to the needs, conflicts and chalenges inherent to education in Information Society. It is focused in the continued formation of teachers, basically in three types of research: education at distance, teachers formation for the use of TIC and 
Digital technologies in music. We sought to discuss the necessary aspects in the proposition of continued formation of teachers, considering their own desire of professional development through bimodal formation and research group structure. For the referred discussion, we used authors such as: Aretio (2001), Gadotti (2003), Scherer (2005), Brito (2006), Brito and Purificação (2006) and Behrens (2007). The analysis permitted us to evince that regardless the categories (inhabitants, passers-by and visitors) in which teachers, guides and tutors are inserted, both in Gepete or Gepetinho, the participators were guided and protected. Action and learning were built in cooperative and collaborative manner, born from desire and professional compromise of each one of the participators to build an education committed with his or her time.

Keywords: Formation of teachers. Bimodal. Educational technologies Research group.

\section{Introdução}

Atualmente, a maioria das licenciaturas possui escassamente, ou não possui, em sua estrutura curricular disciplinas que abordem as Tecnologias de Informação e Comunicação (TIC). As políticas públicas têm apresentado pouca abrangência, sendo baixo o número de parcerias entre universidades e poder público de forma a garantir a formação continuada de professores com o intuito de promover espaços e tempos para reflexão e ação.

Nos corredores e nas salas de aula de nosso País o professor está exposto a uma "solidão" no que diz respeito ao educar em uma sociedade que articula sua comunicação a partir das tecnologias.

Diante da conjuntura de escassez de formação e reflexão acerca do tema a partir das necessidades reais dos professores surgiu o desejo de acolhimento de professores visando a uma formação capaz de discutir tais questões. Desse desejo nasceu o Grupo de Pesquisa Escola Professor e Tecnologias Educacionais (Gepete), no início de 2007.

Ao receber e orientar professores e especialistas de diversas áreas no aprofundamento das reflexões relativas à escola, professores e tecnologias, teve início um movimento impulsionado por uma professora da Universidade Federal do Paraná (UFPR). No transcorrer de dois anos 
foram integrados todos os orientandos do programa de Pós-Graduação em Educação dessa professora e outros professores da UFPR, da PUCPR e da UNERJ-SC, além de professores da educação básica pública e privada. Em 2009, o Gepete acabou por engendrar um grupo de estudos iniciais em pesquisa (grupo de ingresso) chamado Gepetinho.

Algumas das descobertas, experiências e práticas que se desenvolveram desde o surgimento do Gepete até a organização e interação bimodal $^{1}$ do Gepetinho é o que viemos compartilhar por meio deste artigo.

\section{Reflexões acerca do professor e sua formação na sociedade da informação}

Se desejamos "tratar da formação do educador acerca das questões de ordem tecnológica" precisamos refletir sobre "a que educação estamos nos referindo e para que tipo de sociedade" (BRITO, 2006, p. 1). Pois ainda, segundo a autora, "é necessário que o professor entenda a tecnologia como um instrumento de intervenção na construção da sociedade democrática contrapondo-se a qualquer tendência que a direcione ao tecnicismo, à coisificação do saber e do ser humano" (BRITO, 2006, p. 16).

Dessa forma, entendemos que a questão da formação de professores é complexa; não temos como analisá-la desconsiderando as premissas estruturais pelas quais ela se organiza atualmente, como, por exemplo, com o direcionamento autoritário e conservador das políticas públicas de formação docente e a estrutura universitária das licenciaturas.

De acordo com Gadotti (2003), um aspecto que precisamos considerar é o desejo do professor em profissionalizar-se, pois a profissionalização do professor é parte de uma transformação estrutural que não se decreta, é um desejo que se desenrola, principalmente, por meio das opções pessoais dos professores. Sendo assim, a profissionalização não irá desenvolver-se se não for deliberadamente estimulada por projetos e políticas que digam respeito a um processo de formação contínua.

A formação de professores, assim como todos os movimentos acadêmicos, sofre a influencia da ciência, e no nosso tempo foi gerado

\footnotetext{
${ }^{1}$ Segundo SCHERER (2005, p. 11), "Bimodal - parte presencial e parte virtual, favorecendo a aprendizagem e a comunicação entre professores(as) e alunos(as) em ambientes educacionais híbridos”.
} 
pelo pensamento cartesiano e estruturado no paradigma conservador de interpretação da realidade e carrega até os dias atuais "as denominações de treino e de capacitação” (BEHRENS, 2007, p. 441).

Neste momento, a ciência vive um conflito paradigmático no qual dialogam de um lado "uma abordagem conservadora baseada na racionalidade newtoniana cartesiana, e de outro, uma abordagem inovadora que atende a uma visão da complexidade, da interconexão e da interdependência" (BEHRENS, 2007, p. 441). Sendo assim, a

educação herda a visão newtoniano-cartesiana e o determinismo mecanicista que se converte numa forma de conhecimento utilitário e funcional. Nesse modelo conservador, a formação de professores foi designada como treinamento ou capacitação. No paradigma conservador, esses termos têm o sentido de atualização ou de preparo sistemático para determinada tarefa ou atividade (BEHRENS, 2007, p. 442, grifo da autora).

Adentramos a Sociedade da Informação, com a responsabilidade de educar para o domínio e a interpretação desta, mas pautados em um paradigma de interpretação da realidade estruturado na conservação e resistência que direcionaram a ciência, a educação, a cultura e a sociedade na qual estamos inseridos desde 1650. Isso "é a prova de que o paradigma conservador proposto para o ensino universitário está em crise e cabe aos pesquisadores em educação encontrar possibilidades de ajudar os docentes na transição paradigmática para um paradigma inovador" (BEHRENS, 2007, p. 590).

Nesse contexto, o professor precisa de apoio e orientação, pois as práticas até então conhecidas de graduação e formação profissional do professor evidenciam novas demandas às demandas históricas, culturais e sociais do ensinar na Sociedade da Informação. Dada a incerteza do mundo volátil em que vivemos e a necessidade de preparar-se para o trabalho e para "poder ensinar a aprender, o professor precisa de formação continuada" (DEMO, 2007, p. 48), em espaços de reflexão, escuta, cooperação e colaboração que levem em conta que professores na e para a Sociedade da Informação precisam de

[...] conhecimentos emergentes e não-lineares, processos auto-organizacionais que requerem novas abordagens fundamentadas em novos paradigmas da ciência, bem como novas práticas pedagógicas que reconheçam o aprendiz em sua 
multidimensionalidade, ao mesmo tempo em que favorecem a aprendizagem individual e coletiva a partir do balanceamento adequado das dimensões construtiva e informativa dessas ferramentas. Requerem um paradigma educacional que reconheça a natureza viva e transdisciplinar do processo de construção de conhecimento, a interatividade dos processos cognitivos e seja capaz de recuperar a inteireza humana, os valores multiculturais e $\mathrm{o}$ respeito às diferentes maneiras de pensar. Onde aprendizagem e vida já não mais se separam (MORAES, 2000, p. 1).

Porque o "professor, em primeiro lugar, é um ser humano e, como tal, é construtor de si mesmo e da sua história. É criador e criatura ao mesmo tempo: sofre as influências do meio em que vive e com as quais deve autoconstruir-se. [...] o professor é aquele que [...] dá direção ao ensino e à aprendizagem" (BRITO; PURIFICAÇÃO, 2006, p. 37). E se ele deseja buscar o aprimoramento de suas práticas por meio de processos reflexivos inseridos no contexto cultural em que habitam, as instituições de ensino superior e de pesquisa possuem a condição social de possibilitar estes espaços.

\section{A formação do Gepete}

Para o Conselho Nacional de Desenvolvimento Científico e Tecnológico $^{2}(\mathrm{CNPq})$ um grupo de pesquisa pode ser definido como

um conjunto de indivíduos organizados hierarquicamente em torno de uma ou, eventualmente, duas lideranças: cujo fundamento organizador dessa hierarquia é a experiência, o destaque e a liderança no terreno científico ou tecnológico; no qual existe envolvimento profissional e permanente com a atividade de pesquisa; cujo trabalho se organiza em torno de linhas comuns de pesquisa; em algum grau, compartilha instalações e equipamentos. Na quase totalidade desses casos, os grupos se compõem do pesquisador e de seus estudantes. Tratase de um grupo de pesquisadores, estudantes e pessoal de apoio técnico que está organizado em torno à execução de linhas de pesquisa segundo uma regra hierárquica fundada na experiência e na competência técnico-científica. Esse conjunto de pessoas utiliza, em comum, facilidades e instalações físicas (CNPq, 2009).

${ }^{2}$ Disponível em: http:/ /www.cnpq.br acesso em: 2 ago. 2009. 
Levando-se em conta esta definição e a grande procura de informações e orientações na área de educação, formação de professores, escola e tecnologias educacionais, a professora responsável pela disciplina que aborda o referido tema na UFPR, no Programa de Pós-Graduação e Pesquisa em Educação, na linha de pesquisa Cultura, Escola e Ensino, passou a organizar e estruturar a formação do Gepete.

O Gepete teve seu início no ano de 2007, quando cerca de cem professores de diferentes áreas prestaram a seleção para a uma disciplina isolada, ofertada pelo Mestrado em Educação da UFPR, com o objetivo de discutir a tríade professor, escola e tecnologias.

Diante da grande demanda evidenciada, a professora da disciplina convidou esses professores a participar de um grupo de estudos focado na mesma tríade. Aceitaram o desafio de participação no grupo de estudos 18 professores; destes, $21 \%$ estavam em início de carreira (um a cinco anos de experiência) e $79 \%$ com mais de seis anos de experiência profissional.

Com esses dados pode-se definir esses professores como estando em fase de consolidação profissional ou em desenvolvimento profissional.

Odesenvolvimento profissional é um projecto ao longo da carreira desde a formação inicial, à iniciação, ${ }^{3}$ ao desenvolvimento profissional contínuo através da própria carreira... O desenvolvimento profissional é uma aprendizagem contínua, interactiva, cumulativa, que combina uma variedade de formatos de aprendizagem (FULLAN, ${ }^{4} 1987$ apud GARCÍA, 1999, p. 27).

Ao longo do ano de 2007 foram realizados encontros e estudos na modalidade bimodal, ou seja, momentos presenciais e a distância por meio de um Ambiente Virtual de Aprendizagem (AVA).

Os encontros para estudos ocorriam semanalmente, alternando os momentos presenciais e virtuais. Estes estudos e encontros possuíam sua metodologia, didática e referência teórica pautadas em pesquisadores que se fundamentam na consideração de fatores e variáveis culturais que envolvem as discussões, reflexões e práticas que contextualizem os desafios

\footnotetext{
${ }^{3}$ García (1999) descreve o processo de formação de professores em quatro fases: fase de pré-treino - toda a experiência vivida enquanto aluno; formação inicial - fase de preparação formal em instituição específica; fase de iniciação - correspondendo aos primeiros anos de atuação, e a fase de formação permanente ou desenvolvimento profissional.

${ }^{4}$ FULLAN, M. Staff Development innovation and Institutional Development. In: JOYCE, B. School culture Through Staff Development. Virginia: ASCD, 1987.p. 3-25.
} 
e as possibilidades de se fazer educação na Sociedade da Informação. São eles: Alava (2002), Brito e Purificação (2006), Castells (2003) e Sancho (2006), principalmente.

Como síntese dos estudos, em novembro de 2007 foi realizado um seminário socializador para a comunidade educacional, esta compreendendo a educação básica e também o ensino superior do município de Curitiba e mais dois municípios metropolitanos. Finalizado o seminário houve grande interesse da referida comunidade em ingressar no grupo de estudos. Diante disso, o grupo que no fim de 2007 que estava composto por 12 professores decidiu abrir espaço para novos ingressos.

Iniciadas as atividades em 2008, com 23 integrantes de diferentes atuações (educação básica, educação profissionalizantee ensino superior) e formações (graduados, especialistas, mestres e doutores), o grupo de estudos passou a ser um grupo de pesquisa vinculado ao $\mathrm{CNPq}$, contando com 14 pesquisadores e nove estudantes desenvolvendo pesquisas em três diferentes linhas:

- educação a distância;

- formação de professores para o uso das TIC;

- tecnologia digital em música.

Diante da grande procura por participação nos estudos realizados pelo Gepete, os participantes decidem socializar as pesquisas realizadas de uma forma diferente da anterior: seminários temáticos.

Ao todo, durante o ano de 2008, já como grupo de pesquisa e com o ingresso de mais professores doutores, foram realizados quatro diferentes seminários temáticos:

- tecnologias na educação: um repensar;

- formação de professores e as tecnologias;

- eu, professor/professora, preciso de TIC?;

- internet na educação.

Com esses seminários, o grupo de pesquisa conseguiu atingir uma média de cem participantes a cada encontro, um número muito considerável, já que os professores ali estavam por escolha.

Similarmente a procura no início do processo em 2007 e 2008, no ano de 2009 muitos profissionais da educação em contato por meio 
do site do grupo e principalmente por e-mail, bem como, candidatos não ingressos no mestrado em educação demonstraram interesse em participar das discussões e reflexões que seriam realizadas no ano que estava iniciando. Essa situação possibilitou ao grupo a discussão das possibilidades de abertura a novos participantes.

\section{A disseminação: Gepetinho}

Com o progresso nos estudos e pesquisas realizadas ao longo de dois anos pelos integrantes do Gepete, considerou-se pertinente uma iniciação dos estudos para quem estava iniciando, nos mesmos moldes pelos quais haviam passado os primeiros integrantes no início do grupo de pesquisa. Assim, o relato detalhado que segue é embasado nas experiências bimodais eos dados recolhidos da experiência dizem respeito ao processo de constituição do Gepetinho.

O Gepetinho é o grupo de profissionais da educação que participou no primeiro semestre de 2009 da iniciação à pesquisa sobre a escola, professor e tecnologias educacionais e que foi orientado pelos pesquisadores do Gepete.

A interação dos participantes, no sentido de ter acesso aos materiais, textos, agenda e base de dados gerais do grupo que estava se constituindo, ocorreu de forma bimodal, ou seja, segundo Scherer (2005), os membros do grupo puderam interagir em suas construções e reflexões tanto na modalidade presencial em reuniões e seminários, como na modalidade a distância por meio de um AVA. ${ }^{5}$

Para que estes encontros bimodais pudessem acontecer, três mestrandas na área de Educação e Tecnologias estiveram à disposição do grupo desempenhando o papel da tutoria a distância, organizando, alimentando, interagindo, colaborando e cooperando por meio de diferentes ferramentas disponíveis no AVA, com o objetivo de fomentar, institucionalizar, organizar e concluir as atividades que eram desenvolvidas a cada quinzena, de março até julho de 2009.

\footnotetext{
${ }^{5}$ São sistemas que sintetizam a funcionalidade de software para Comunicação Mediada por Computador (CMC) e métodos de entrega de material e cursos online. Muitos desses sistemas reproduzem a sala de aula presencial física para o meio online; outros buscam, além de simplesmente reproduzir ambientes educacionais existentes para um novo meio, usar a tecnologia para propiciar aos aprendizes novas ferramentas que facilitem a aprendizagem. Esses últimos procuram suportar uma grande e variada gama de estilos de aprendizagem e objetivos, encorajando a colaboração, a aprendizagem baseada na pesquisa, além de promover o compartilhamento e reuso dos recursos (SCHLEMMER, 2005, p. 137).
}

Rev. Diálogo Educ., Curitiba, v. 10, n. 31, p. 505-520, set./dez. 2010 
As tutoras procuraram exercer seu papel de forma consciente, uma vez que um tutor pode auxiliar os participantes de processos na modalidade a distância a estabelecer as interações necessárias com os orientadores, com os outros participantes, com os conteúdos e ferramentas disponíveis no AVA, "fornecendo aos mesmos a possibilidade de saírem de uma dimensão descritiva e ingênua, para uma dimensão analítica" como participantes em um processo de discussão e reflexão como este (ARETIO, 2001).

Para tanto, o papel das tutoras do Gepetinho se constituiu da busca da alta interação, constituindo grupos cooperativos e colaborativos, despertando a autonomia e desencadeando uma produção conjunta de emissão-recepção-emissão, buscando ser o apoio para um movimento de formação. De acordo com Aretio (2001), isso tem como finalidade primordial incentivar o participante a motivar-se, coparticipar, facilitar e avaliar sua aprendizagem.

A pesquisadora doutora responsável pelo movimento, tanto do Gepete quanto do Gepetinho, acompanhou e orientou os encontros e atividades bimodais e a partir da troca de e-mails com as tutoras.

\section{As experiências}

As atividades do Gepetinho iniciaram com um encontro presencial com a participação de 28 profissionais da educação. Houve um momento de explanação das características dos estudos e pesquisas realizadas pelo grupo, e três profissionais desistiram já no encontro introdutório, por não terem considerado as pesquisas do grupo pertinentes para seus interesses de estudo e/ou formação. Nos encontros seguintes, com os demais ingressos, o grupo totalizou 39 participantes.

Esses profissionais receberam por e-mail um material explicativo sobre os procedimentos de acesso ao AVA, bem como orientações sobre os primeiros movimentos de estada no referido ambiente: login, conhecimento da agenda/calendário de atividades presenciais e virtuais, apresentação em fórum e preenchimento de perfil com upload de imagem.

As atividades de apresentação no fórum e preenchimento do perfil foram realizadas com o objetivo de identificar os professores ingressos no

${ }^{6}$ Upload consiste no processo inverso ao download, ou seja, é aquele em que a pessoa envia o arquivo para a internet. 
Gepetinho e principalmente mapear: formação inicial, área de atuação, experiência em formação bimodal, experiência em AVA e o conceito de tecnologia de cada um dos participantes.

Diante disso, a equipe do Gepete responsável pelo Gepetinho questionou as formas de participação dos professores em formação, bem como dos coordenadores da formação.

Esse questionamento surgiu a partir da definição de Scherer (2005) acerca de formações em ambientes presenciais e também virtuais de aprendizagem. Consideramos importante destacar o uso do termo "quem de nós" na questão problematizadora, por considerarmos a premissa de que o professor mediador, ao desempenhar suas atividades em AVA, pode ter sua atuação inclusa nessas categorias de participação.

De acordo com Scherer (2005), podemos definir os habitantes como aqueles que se responsabilizam pelas suas ações e pelas dos parceiros, buscando o entendimento mútuo, a ação comunicativa, o questionamento reconstrutivo, bem como sendo parte (sentido dinâmico) do ambiente. $\mathrm{O}$ habitante encontra-se sempre no ambiente, pois, de acordo com a autora, ele também vive lá, observando, falando, silenciando, postando mensagens, refletindo, questionando, produzindo, sugerindo, contribuindo com a história do ambiente, do grupo e dele. Dessa forma, o habitante de ambientes de aprendizagem, assim como do mundo, não apenas vive nos ambientes, existe neles.

Já os visitantes são aquele(as) alunos(as) e professores(as) que participam do ambiente de aprendizagem com a intenção de visitar. Para Scherer (2005), essa visita existe quando somos impelidos por algum dever, por afeto ou por amizade. A participação do visitante está em apenas observar o que estava acontecendo, sem se corresponsabilizar com o ambiente, com o outro, ou com a produção coletiva. Ainda assim, muitos deles chegam a colaborar, mas sem chegar a cooperar com o grupo, pois são parte (sentido estático, momentâneo), algumas vezes, do ambiente; não estão sendo parte do ambiente continuamente, eles não habitam o lugar, o conteúdo, pois são visitantes.

Por fim, os transeuntes, seriam os(as) alunos(as) e professores(as) que passam pelo ambiente. Alguns entram, circulando pelos espaços, outros apenas passam. Os transeuntes passam pelo ambiente em um ou mais momentos, às vezes param para observar, mas sem se deter em nenhum espaço em especial, sem se responsabilizar, sem apreender para sio ambiente, 
sem colaborar ou cooperar. São parecidos com os “zapeadores”, aqueles que praticam o zapping com a televisão, internet, trocando de espaços sem uma intenção em específico, sem saber para onde ir.

Por meio desse embasamento, o próximo passo foi analisar os dados disponíveis no AVA.

\section{Os dados da experiência}

Após um semestre de atividades, estudos e seminário, foi possível obter dados quantitativos que forneceram a base para a análise qualitativa da experiência de formação. Os referidos dados dizem respeito:

- ao número de participantes iniciais e finais;

- número de tutores a distancia e professor orientador;

- participantes nas atividades e estudos realizados em AVA;

- participantes no seminário presencial.

Ogrupo de professores que se inscreveu no início do ano participou de todo o processo, finalizando-o com a apresentação do seminário no mês de julho, sendo formado por: um profissional com formação militar, um com formação em Administração, oito com formação em Pedagogia, um em Turismo, três em Matemática, um em Engenharia Civil, dois em Educação Artística, um em Letras e um em Direito.

A experiência ou não do grupo em espaços de reflexão e interação bimodais pode ser declarada como: 16 nunca haviam tido esta oportunidade e três declararam que já tinham participado, mas somente em espaços totalmente a distância.

Dos 19 professores, 18 declaram a experiência como produtiva, de alto e médio índice de aproveitamento; apenas um professor considerou de baixo rendimento, "pois no primeiro semestre estive com uma demanda de trabalho grande".

Quanto ao acesso ao AVA, o grupo considerou como sendo de nível médio e fácil, quando comparado a experiências anteriores em processos de formação na área de tecnologias. Dos que declararam como sendo médio o grau de dificuldades para acessar, postar e interagir com o grupo e com as tutoras por meio do AVA, estes em sua maioria (mais de 50\% do grupo) não haviam ainda tido a oportunidade de realizar um processo 
de formação que utilizasse a proposta bimodal como eixo metodológico. Os que declaram como sendo fácil o acesso e interação via AVA já haviam participado de experiências anteriores semelhantes.

Um dos dados relevantes na experiência, em termos de identificação entre os membros do grupo com a estrutura metodológica proposta, foi a solicitação de um número maior de chats, em substituição aos encontros presenciais offline. Ou seja, os dados deixaram claro que para os professores os chats foram esclarecedores e pertinentes. Descreveram ainda que as discussões que ocorreram neste ambiente fizeram diferença na reelaboração e reestruturação dos conceitos e das temáticas propostas. O único depoimento contrário a esta solicitação do grupo foi de uma professora que declarou dificuldade em participar da dinâmica do grupo, pois classificou o diálogo no chat como sendo muito rápido para sua velocidade de digitação para as respostas.

Finalizando as análises, os professores expressaram a vontade da continuação das discussões e reflexões sobre as seguintes temáticas:

- divulgação e reflexão dos trabalhos do grupo de composição do Gepete, seus doutores e mestres (desejo de ter acesso às pesquisas que deram origem à formação inicial do grupo);

- temas que tratem de TIC e desenvolvimento cognitivo.

Com esses dados, foi possível verificar que $48 \%$ do total de professores iniciantes concluiu o processo participando de todas as atividades e do seminário, dado considerável visto que a formação era de participação voluntária e de interesse dos professores.

Salientamos que, com o grupo de professores inscritos e os integrantes do Gepete, fizeram parte dessa experiência 51 profissionais da educação diretamente ou indiretamente atuantes em sala de aula (educação básica e/ou superior). Finalizadas as atividades, apenas dois participantes requisitaram de forma oficial o desligamento das atividades.

Como relatamos anteriormente, uma das atividades de ambientação foi a apresentação em fórum. Na referida atividade destacamos um dado que nos chamou muito a atenção: obtivemos 36 respostas considerando a apresentação das tutoras. Isso equivale a $86 \%$ do total de participantes. No entanto, o número de visualizações foi equivalente a 36 vezes o número de postagens, sendo igual a 1.330 visualizações. 
Levando-se em conta o número de participantes inscritos no processo, podemos dizer que seis deixaram de realizar sua apresentação. Todavia, as descrições de cada membro do grupo foram visualizadas 332 vezes por mês, ou seja, havia grande curiosidade no sentido de diagnosticar quem eram os integrantes deste grupo.

Essa característica de alto número de visualizações e reduzido número de postagens efetivas se repetiu no fórum sobre o perfil dos participantes: obtivemos três respostas, no entanto, quase cem vezes mais visualizações, perfazendo um total de 257 . Isso aponta para a característica de grande movimento de observação pelos integrantes deste processo - uma curiosidade que nos leva a refletir a partir dos conceitos mencionados de Scherer (2005): quem no grupo, a partir deste foco, poderia ser mencionado como visitante, transeunte ou habitante? Aquele que esteve no ambiente apenas no momento em que cumpriu a atividade e não mais voltou poderia ser considerado habitante? E como poderíamos caracterizar o movimento daquele que visitava o ambiente diariamente para observar a atuação dos colegas, mas por motivos particulares não desejou desenvolver as tarefas? Quais destes participantes seriam visitantes e quais seriam habitantes?

No entanto, o fator relevante neste processo é que, seja qual for a categoria em que professores, orientadores e tutores se encaixem (habitantes, transeuntes ou visitantes), tanto o Gepete quanto o Gepetinho acolheram, orientaram e ampararam os participantes desta jornada, em um espaço/ tempo bimodal, construído de maneira cooperativa e colaborativa, nascido do desejo que "mora" no compromisso profissional de cada um destes indivíduos em construir uma educação comprometida com seu tempo.

\section{Considerações finais}

Após essa experiência de formação em grupo de pesquisa e das reflexões baseadas nos questionamentos suscitados, entendemos que apesar de ser evidente o grande número de visualizações no AVA, podendo ser caracterizado como um movimento visitante, o grupo foi composto tanto por habitantes como por visitantes e também de transeuntes. E a essas categorias não aplicamos apenas os professores em formação, mas também os tutores, como muito salienta Scherer (2005). Sem sombra de dúvida, um dos objetivos de formações bimodais e em grupo de pesquisa 
é a garantia de efetiva produção e ampliação de conhecimento. Sendo assim, há que se pensar em práticas que levem os professores em formação a serem de fato habitantes. Isso porque nesse estágio inicial todos os movimentos foram considerados e respeitados, fossem eles de visitantes, de transeuntes ou de habitantes.

Uma questão que emergiu após essa experiência é como devem ser as práticas, em formações como essa, para que efetivem grande número de habitantes tanto em AVA como presencial. Até porque "temos certeza de que aqueles que se dedicarem consciente e prazerosamente à conquista das tecnologias na educação jamais sofrerão abandono e a solidão (e suas conseqüências) a que estão condenados no sistema tradicional" (BRITO; PURIFICAÇÃO, 2006. p.99).

\section{Referências}

ALAVA, S. Ciberespaço e formações abertas: rumo a novas práticas educacionais. Porto Alegre: Artmed, 2002.

BEHRENS, M. A. O paradigma da complexidade na formação e no desenvolvimento profissional de professores universitários. Educação, v. 30, n. 3. p. 439-455, 2007.

BRITO, G. da S.; PURIFICAÇÃO, I. da. Educação e novas tecnologias: um repensar. Curitiba: IBPEX, 2006.

BRITO, G. da S. Tecnologias da comunicação e informação: controle e descontrole. Inclusão digital do profissional professor: entendendo o conceito de tecnologia. In: ENCONTRO ANUAL DA ANPOCS, 30., 2006, Caxambu, MG. Anais... Caxambu, MG: GT24, 2006.

CASTELLS, M. A galáxia internet: reflexões sobre a internet, os negócios e a sociedade. Rio de Janeiro: Jorge Zahar, 2003.

DEMO, P. Desafios modernos da educação. 14. ed. Petrópolis: Vozes, 2007. GADOTTI, M. Pedagogia da práxis. São Paulo: Cortez, 2003.

GARCÍA, C. M. Formação de professores: para uma mudança educativa. Porto: Porto Editora, 1999. 
GARCIA ARETIO, L. La educación a distancia: de la teoría a la práctica. Barcelona: Ariel Educación, 2001.

MORAES, M. C. de. Pensamento eco-sistêmico: educação, aprendizagem e cidadania no século XXI. Petrópolis: Vozes, 2004.

SANCHO, J. M.; HERNANDEZ, F. Tecnologias para transformar a educação. Porto Alegre: Artmed, 2006.

SCHERER, S. Uma estética possível para a educação bimodal: aprendizagem e comunicação em ambientes presenciais e virtuais. Uma experiência em estatística aplicada à educação. São Paulo, 2005. 241 f. Tese (Doutorado em Educação) Pontifícia Universidade Católica de São Paulo, São Paulo, 2005.

SCHLEMMER, E. Ambiente virtual de aprendizagem (AVA): uma proposta para a sociedade em rede na cultura da aprendizagem. In: VALENTINI, C. B.; SOARES, E. M. do S. (Org.). Aprendizagem em ambientes virtuais: compartilhando idéias e construindo cenários. Caxias do Sul: EDUCS, 2005.

Recebido: 10/04/2010

Received: 04/10/2010

Aprovado: 20/06/2010

Approved: 06/20/2010 